\title{
Efficacy of emergency laparoscopic appendectomy in treating complicated appendicitis for elderly patients
}

Tian-Chong Wu, PhD, Qiao Lu, MD, Zhi-Yong Huang, MD, Xio-Hui Liang, MM.

\section{ABSTRACT}

الأهداف : لتقييم الآثار العلاجية لحالات استئصال الزائدة

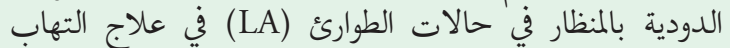

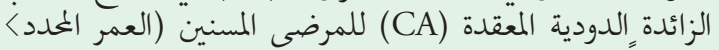
. 65 عاماً الرودية)

الطريقة : أجرينا دراسة استعادية لعدد 115 مريضا من كبار

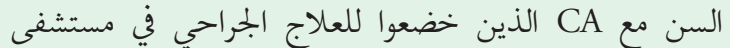

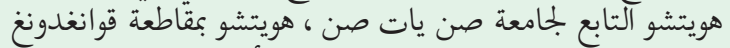

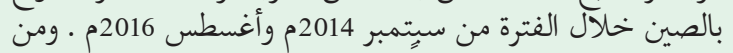
بين هؤلاء ، وافق 59 مريضاً على فتح المتح استئصال الزائدة الدودية

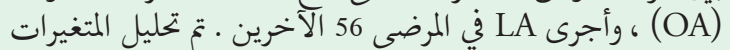

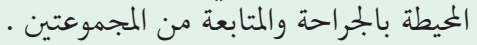

النتائج : كان وقت العملية في مجموعة LA أطول من من مجموعة

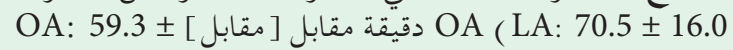

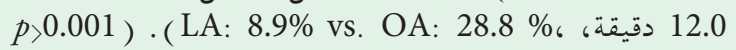

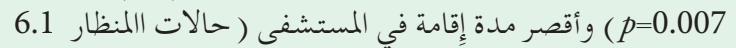

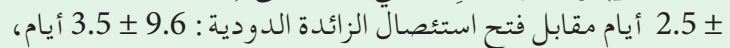

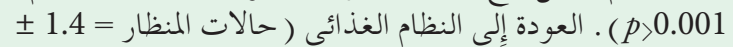

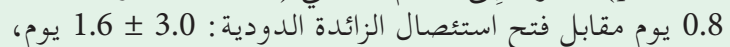

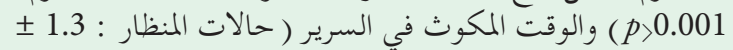

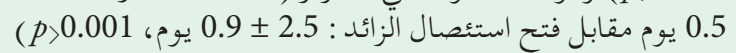

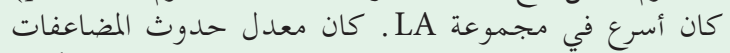

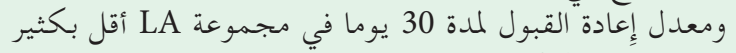
من مجموعة OA.

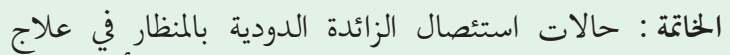

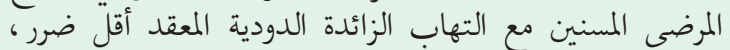

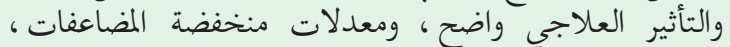
والرجوع السريع بُألمقارنة مع فتح استئصال الزائدة الدودية .

Objective: To assess the therapeutic effects of emergency laparoscopic appendectomy (LA) in treating complicated appendicitis (CA) for elderly patients (defined as age $\geq 65$ years).
Methods: We conducted a retrospective study of 115 elderly patients with CA who underwent surgical therapy in the Affiliated Huizhou Hospital of Sun Yat-Sun University, Huizhou, Guangdong Province, China between September 2014 and August 2016. Of these, 59 patients consented to open appendectomy (OA), and LA was performed in the other 56 patients. The perioperative and follow-up variables of the 2 groups were analyzed.

Results: The operative time in the LA group was longer than the OA group (LA: $70.5 \pm 16.0$ min versus [vs.] OA: $59.3 \pm 12.0 \mathrm{~min}, p<0.001)$. The LA group had lower chances of incision infections (LA: $8.9 \%$ vs OA: $28.8 \%, p=0.007)$ and shorter hospital stay (LA: $6.1 \pm 2.5$ days vs. OA: $9.6 \pm 3.5$ days, $p<0.001)$. Return to soft diet (LA: $1.4 \pm 0.8$ days vs OA: $3.0 \pm 1.6$ days, $p<0.001)$ and time to out of bed (LA: $1.3 \pm 0.5$ days vs OA: $2.5 \pm 0.9$ days, $p<0.001$ ) was faster in the LA group. The incidence of complications and 30-day readmission rate in the LA group was much lower than the OA group.

Conclusion: Emergency LA in treating elderly patients with CA has the advantages of less trauma, definite curative effect, low complication rates, and fast recovery when compared with OA.

Saudi Med J 2017; Vol. 38 (11): 1108-1112 doi: 10.15537/smj.2017.11.20469

From the Department of Hepatobiliary and Pancreatic Surgery (Wu), The Second Medical College, Shenzhen People's Hospital, Jinan University, Shenzhen, and the Department of Gastrointestinal Surgery (Lu, Huang, Liang), Huizhou Municipal Central Hospital, Affliated Huizhou Hospital of Sun Yat-sun University, Huizhou, Guangdong Province, China.

Received 15th June 2017. Accepted 22nd August 2017.

Address correspondence and reprint request to: Dr. Tian-Chong Wu, Department of Hepatobiliary and Pancreatic Surgery, Shenzhen People's Hospital, Jinan University, Shenzhen, Guangdong Province, China. E-mail: drwutianchong@sina.com 
C omplicated appendicitis (CA) is one of the most common types of acute appendicitis in elderly patients. Appendectomy is one of the most common emergency surgical procedures. With the application of laparoscopic surgery in abdominal surgery more and more widely used, questions have repeatedly been raised on whether open appendectomy (OA) is still the most effective method for elderly patients. ${ }^{1}$ Although the first laparoscopic appendectomy (LA) was performed in 1983, the debate continues on which surgical approach provides better management of this condition. ${ }^{2}$ Many factors including better health insurance, China's baby boom, and expectancy of longer life, have resulted in an apparent increase in the aged population. ${ }^{3}$ Appendectomy in the elderly is relatively increasing because of the aged tendency of population and the trend of relatively high lifetime. Elderly surgical patients tend to have increased comorbidity, less physiologic reserve, altered nutritional status, and an increased incidence of postoperative morbidity and mortality compared with younger patients. ${ }^{4}$ Reported complication rates after OA in elderly patients are $12-74 \%$, with a mortality rate of up to $14 \% .^{5}$ Although previous studies have shown that LA is a preferred treatment method for uncomplicated appendicitis, and LA is linked with reduced probability of incision infection, decreased need for postoperative analgesics, quicker state recovery and better cosmetic effect compared with OA. However, these results are merely appropriate measures for young patients, their relevance as measures of quality of care and patient safety management in CA treatment of elderly patients, especially in an emergency, remains undefined. ${ }^{6}$ Our department began treating CA for elderly patients with emergency LA in 2014. Between 2014 and 2016, a total of 56 elderly patients with CA underwent LA, and 59 elderly patients with CA were treated with $\mathrm{OA}$, which comprised the control group for the corresponding period. We conducted a retrospective study and collected related data for comparative analysis between the 2 groups. The purpose of this study is to validate the safety and effectiveness of emergency LA for CA in treating elderly patients.

Methods. Patients. We conducted a retrospective observational study of elderly patients (defined as age $\geq 65$ years) admitted to a single organization (Department of Gastrointestinal Surgery, Affiliated Huizhou Hospital of Sun Yat-Sun University, Huizhou, Guangdong Province, China) between September 2014 and August 2016 with the diagnosis of CA. Complicated appendicitis was defined as the presence of secondary intra-abdominal abscesses or peritonitis secondary to intraperitoneal inflammation. Gangrene or perforation of the appendix was confirmed by microscopic examination, according to the American Society of infectious diseases. ${ }^{7}$ The inclusion criteria were (1) 65 years old or older; (2) compliant with the definition of CA; (3) sufficiently healthy to undergo surgery. The exclusion criteria were (1) diagnosis other than CA, and (2) inability to provide informed consent. One hundred and fifteen elderly patients met the inclusion criteria. Each patient signed a medical informed consent before the surgical procedure. The ethics committee of the Affiliated Huizhou Hospital of Sun Yat-sun University approved this study.

Surgical techniques. A right lower paramedian incision was carried out in OA group. The mesoappendix and the appendiceal stump were ligated with silk subsequently. Finally, absorbable sutures were utilized to seal the abdominal wall in layers. Routinely, the skin was sutured with non-absorbable sutures. For the LA, an incision about $10-\mathrm{mm}$ was performed in the umbilicus, then a $10-\mathrm{mm}$ trocar was inserted where the abdominal wall was lifted. A laparoscopic camera was carefully put into the intraperitoneal space via the $10-\mathrm{mm}$ trocar. Carbon dioxide (CO2) set to $11 \mathrm{~mm} \mathrm{Hg}$ was utilized to inflate the intraperitoneal space. In addition, $25-\mathrm{mm}$ trocars were inserted through the McBurney's point and suprapubic region. Patients were placed in a 30-degree Trendelburg position and tilted to the left by 15 degrees. The mesoappendix was anatomized using a dissector with electrocautery. The appendix was double ligated with silk and then removed using surgical scissors. To prevent contamination, the excisional appendix was packed into a specimen bag and pulled out through the $10-\mathrm{mm}$ trocar. All specimens were examined pathologically. Pelvic drainage tubes were placed in both groups.

Analgesics were administered orally or parenterally. Continuing or discontinuing use of antibiotics was based on the clinical presentation. Oral ingestion was initiated when the patient was able to tolerate, or as soon as bowel function was restored. The patients were discharged from hospital when they were given adequate oral intake and fully mobilized. Complications after operation were recorded in detail during and after hospitalization. Follow-up was at one week, 15 days, one month and 3 months.

Statistical analysis. Chi-square test was used to compare categorical data, while data of continuity shown as the mean \pm standard $( \pm S)$ deviation were evaluated by Student's $t$ test. The comparisons between the 2 groups were based on intention to treat. Therefore, the cases converted to open procedure in LA group were 
not removed from the analysis. $P<0.05$ was set as the level of statistical significance. The Statistical Package for Social Sciences 13.0 software (SPSS Inc., Chicago, IL, USA) was utilized to perform all calculations.

Results. Comparison of clinical indexes. There were 115 elderly patients with CA that met the inclusion criteria and received surgical intervention. A total 56 patients received LA, and 59 patients received OA. No statistically significant difference was observed in the clinical characteristics and other criteria $(p>0.05)$. According to the type of CA, there was no statistical difference between the 2 groups $(p>0.05)$. The detailed comparison is shown in Table 1.

Comparison of curative effect. Laparoscopic appendectomy took longer to perform, but the duration of pain was with significantly shorter, and the time to leave bed was earlier $(p<0.05)$. The LA group took less time to begin taking a soft diet than the OA group $(p<0.05)$. The hospital stays of the LA group were also

Table 1 - Clinical and pathological features of the LA and OA groups.

\begin{tabular}{|c|c|c|c|}
\hline Characteristics & $\begin{array}{c}\mathrm{LA} \\
(\mathrm{n}=56)\end{array}$ & OA $(n=59)$ & $P$-value \\
\hline Age (years) & $70.6 \pm 4.4$ & $71.8 \pm 4.9$ & 0.174 \\
\hline Male & $34(60.7)$ & $34(57.6)$ & 0.736 \\
\hline \multicolumn{4}{|l|}{ Comorbidity } \\
\hline Hypertension & $21(37.5)$ & $25(42.4)$ & 0.594 \\
\hline Diabetes mellitus & $13(23.2)$ & $14(23.7)$ & 0.984 \\
\hline Coronary artery disease & $1 \quad(1.8)$ & $3 \quad(5.1)$ & 0.335 \\
\hline Chronic renal failure & (3.6) & (5.1) & 0.525 \\
\hline $\begin{array}{l}\text { Chronic obstructive } \\
\text { pulmonary disease }\end{array}$ & $(8.9)$ & $(6.8)$ & 0.467 \\
\hline \multicolumn{4}{|l|}{ ASA class } \\
\hline I & 51 & 51 & 0.433 \\
\hline II & 5 & 7 & 0.607 \\
\hline III & 0 & 1 & 0.513 \\
\hline $\mathrm{IV} / \mathrm{V}$ & 0 & 0 & 0 \\
\hline Duration of symptoms (day) & $3.0 \pm 1.2$ & $3.1 \pm 1.4$ & 0.570 \\
\hline Previous abdominal surgery & $6(10.7)$ & $10(16.9)$ & 0.334 \\
\hline \multicolumn{4}{|l|}{ Preperative clinical findings } \\
\hline $\begin{array}{l}\text { Right lower quadrant } \\
\text { tenderness }\end{array}$ & $37^{(66.1)}$ & $36^{(61.0)}$ & 0.574 \\
\hline Body temperature $\left({ }^{\circ} \mathrm{C}\right)$ & $37.8 \pm 0.8$ & $37.9 \pm 0.7$ & 0.540 \\
\hline White blood cell $(\times 10 / \mathrm{ul})$ & $12.6 \pm 2.2$ & $12.5 \pm 2.6$ & 0.804 \\
\hline $\begin{array}{l}\text { Appendiceal abscess diameter } \\
(\mathrm{cm})\end{array}$ & $4.6 \pm 0.9$ & $4.5 \pm 1.1$ & 0.701 \\
\hline \multicolumn{4}{|c|}{ Intraoperative \& pathological findings } \\
\hline Gangrene & $19(33.9)$ & $14(23.7)$ & 0.227 \\
\hline Perforated & $32(57.1)$ & $39(66.1)$ & 0.323 \\
\hline Periappendiceal abscess & $5 \quad(8.9)$ & $6(10.2)$ & 0.821 \\
\hline Drainage insertion & $42(75.0)$ & $46(78.0)$ & 0.708 \\
\hline \multicolumn{4}{|c|}{$\begin{array}{c}\text { LA - laparoscopic appendectomy, OA - open appendectomy, } \\
\text { data are } \mathrm{n}(\%) \text { or mean } \pm \text { standard deviation, ASA - American Society of } \\
\text { Anesthesiologists }\end{array}$} \\
\hline
\end{tabular}

Table 2 - Surgical and postoperative clinical data.

\begin{tabular}{|c|c|c|c|}
\hline Variable & LA $(n=56)$ & OA $(n=59)$ & $P$-value \\
\hline Operative time (min) & $70.5 \pm 16.0$ & $59.3 \pm 12.0$ & $<0.001$ \\
\hline Duration of pain (day) & $1.7 \pm 0.7$ & $3.9 \pm 1.0$ & $<0.001$ \\
\hline Time to soft diet (day) & $1.4 \pm 0.8$ & $3.0 \pm 1.6$ & $<0.001$ \\
\hline Time to leave bed (day) & $1.3 \pm 0.5$ & $2.5 \pm 0.9$ & $<0.001$ \\
\hline Hospital stay (day) & $6.1 \pm 2.5$ & $9.6 \pm 3.5$ & $<0.001$ \\
\hline Intensive Care Unit & $6 \quad(10.7)$ & $(27.1)$ & 0.025 \\
\hline Readmission & (3.6) & $10 \quad(16.9)$ & 0.019 \\
\hline
\end{tabular}

significantly shorter $(p<0.05)$. The detailed comparison is shown in Table 2.

Comparison of complications. The LA group had a lower rate of wound infections compared with the OA group $(p<0.05)$. All wound infections in the LA group were limited to the skin level, and no wound dehiscence was detected. However, incision infections did develop among the converted patients. There were 2 patients of the LA group, and 17 of the OA group that required secondary suturing and the rest were dressed with conservative treatment. In the LA group, 7 cases had intra-abdominal abscess, with 14 cases in the OA group. The patients with abdominal abscess were cured successfully by percutaneous puncture and drainage, and no one underwent reoperation because of the complications. Three cases in the LA group, and 12 cases in the OA group had prolonged ileus after operation that delayed the start time of soft diet. Among the 15 cases of prolonged ileus, 10 cases recovered by treating with mere fasting and intravenous fluids, however, the other 5 cases need to be treated with nasogastric tube insertion. In addition, there were 4 patients in the LA, and 5 patients in the OA group that developed postoperative jaundice. Six cases in the LA group, and 16 in the OA group with comorbidity needed ICU support treatment. Another 4 patients in the LA group, and 14 patients in the OA group developed postoperative chest infection and needed additional antibiotics. In the LA group, 2 patients with intra-abdominal abscess were readmitted with fever and abdominal pain. The intraabdominal abscess was verified by abdominal CT. The abscesses were treated only by intravenous antibiotics, and when the physical examination, blood tests, and abdominal ultrasound examination confirmed that the infection was eliminated, the treatment was stopped. The LA group had significantly lower complication rates $(p<0.05)$. There was no postoperative mortality in 2 groups. Detailed data are shown in Table 3. 
Table 3 - Postoperative complications.

\begin{tabular}{lcrrrc}
\hline Variable & \multicolumn{1}{l}{ LA $(\mathrm{n}=56)$} & \multicolumn{2}{c}{ OA $(\mathrm{n}=59)$} & $P$-value \\
\hline Incision infections & 5 & $(8.9)$ & 17 & $(28.8)$ & 0.007 \\
Intra-abd Abscess & 7 & $(12.5)$ & 14 & $(23.7)$ & 0.119 \\
Prolonged Ileus & 3 & $(5.4)$ & 12 & $(20.3)$ & 0.017 \\
Jaundice & 4 & $(7.3)$ & 5 & $(8.5)$ & 0.790 \\
Postoperative Chest & 4 & $(7.3)$ & 14 & $(23.7)$ & 0.016 \\
Infection & 0 & 0 & 0 & 0 & - \\
Mortality & \multicolumn{7}{c}{ data are n (\%) } \\
\hline
\end{tabular}

Discussion. Existing studies have shown that LA is superior to OA in reducing the likelihood of surgical site infection, reducing the need for postoperative analgesics, and providing faster recovery of preoperative functional status. ${ }^{8}$ However, few studies have paid attention to the elderly population; although these outcomes may be advisable measures for young patients, further comparative measures are needed to ensure the safety of elderly patients under the context of novel surgical techniques in emergency cases. Complicated appendicitis is closely related to the occurrence of postoperative complications, which has been regarded as a relative contraindication for emergency LA, especially in the elderly population. At present, OA is still widely used in clinical practice. ${ }^{9}$ Nonetheless, this concept has been challenged by several studies by comparing the surgical results of LA with CA. Some authors have shown that LA is safe and leads to faster recovery with decreasing wound infection. ${ }^{10,11}$ However, other authors, found no significant differences in the results of the 2 surgical procedures and noticed that the hospitalization expenses of LA were higher, which have challenged the above studies. ${ }^{12,13}$

In our series, the total operative time in the LA group was significantly longer the OA group $(p<0.001)$. In general, procedures performed by inexperience surgeons usually result in a longer time for the laparoscopic operation. In the current research, by contrast, the impact of practice curve was minimal for the surgeons with extensive experience in laparoscopic surgery, such as gastrectomy and colectomy surgery. Therefore, the longer operative time of LA in our study may be caused by additional surgical procedures including insufflation, instrument setting, inseting trocars under vision, and laparoscopic exploration of abdominal cavity. Especially in the case of CA, the laparoscopic dissection technique is more complex, and time-consuming. Aziz et $\mathrm{al}^{14}$ strongly emphasized that the advantages of laparoscopic surgery have nothing to do with the operative time. Another undisputed advantage is that, for suspected cases, LA enables the performance of diagnostic laparoscopy before the operation begins. A key factor that directly affects the costs and the quality of life is the length of hospital stay. We detected that the hospitalization time in the LA group was significantly shorter $(p=0.015)$ with earlier bowel function recovery and shorter time to leave bed in patients managed with LA $(p<0.001)$, resulting in earlier eating $(p<0.001)$ and earlier hospital discharge $(p<0.001)$. Our clinical research is consistent with several studies that shows, even in elderly patients, LA also can significantly shorten the length of hospital stay. ${ }^{15,16}$ In our surgical department, postoperative pain was assessed by subjective visual analogue scale, and a list of objective analgesics was used. In the current study, we found that the duration of pain may affect the patient's enthusiasm for a new treatment technique. ${ }^{1,7,8}$ In this series, we use only a small amount of oral or parenteral analgesics according to the individual needs. The duration of pain was shorter in the LA group $(p<0.001)$, which was in accordance with other studies. ${ }^{7-10}$

In our study, the mortality rate was nil, which indicated that emergency appendectomy, even in elderly patients, is also a safe procedure regardless of which technique was used. Although incision infection is more common in CA, and is not a severe complication, it has a great influence on the recovery time and living quality. ${ }^{17}$ The incision infection rate in the group LA was less than that in the OA group $(p=0.007)$, which could be due to the use of a specimen bag when removing the appendix, which prevented close contact of the surgical specimen with the wound. It is easy to completely clean the infected fluid in the abdominal cavity in LA. In contrast; it is hard to avoid abdominal wound contact with the infectious liquid and purulent appendix in the OA group. The rate of wound infection in the OA group is as high as $43.6 \%$ in existing reports. ${ }^{17}$ Intra-abdominal abscess, which is a severe life-threatening complication for elderly patients, is associated with the need for consequent interventions and readmissions. We found 7 cases $(12.5 \%)$ of the LA group and 23 cases (23.7\%) of the OA group with postoperative intra-abdominal abscess. These results were dissimilar to the existing research that showed LA is associated with a growing risk of intraperitoneal abscess compared with OA. ${ }^{7,8,10}$ Several hypotheses have been proposed to seek out possible explanations. As the infected area has severe peritonitis, carbon dioxide insufflations promote mechanical spread of bacteria, especially in case of CA, insufficient learning curve, the excessive peritoneal lavage and simple abdominal suction often lead to contamination of the abdominal 
cavity. ${ }^{10,15,18}$ In addition, abdominal infection is often difficult to completely drain, and can easily lead to the formation of an intra-abdominal abscess. ${ }^{18}$ In all cases, we performed a thorough peritoneal lavage after removal of the specimen. However, in our study there was no difference between the 2 groups in the incidence of intra-abdominal abscess $(p=0.119)$. Although some studies have shown that laparoscopic treatment has a higher incidence of intra-abdominal abscess, ${ }^{7,8,10,18}$ combined with the results of this study, it may be not true. The first choice for the treatment of abdominal abscess is percutaneous abdominal abscess drainage, followed by surgical treatment. ${ }^{19}$ Preoperative or postoperative antibiotics or abdominal abscess drainage was performed in our study. There are other observed complications after operation such as paralytic ileus, jaundice, and postoperative chest infection (Table 3). As a less invasive alternative, the LA group had less postoperative chest infections $(p=0.016)$ and ICU support $(p=0.025)$ than the OA group. Furthermore, the 30-day readmission rate was much lower in patients who had undergone LA ( $p=0.019)$. A limitation of our study is its retrospective nature. It also does not consider the long-term efficacy and impact on health care costs.

In conclusion, we compared the outcomes between laparoscopic and OA for emergency treatment of CA in elderly patients. Our results show that compared with conventional OA, emergency LA is secure and effective in the therapy of CA in elderly patients, and has the advantages of lower incidence of infection complications and faster recovery. Moreover, we detected a considerable preference consent to laparoscopic surgery of elderly patients and the satisfaction of LA group was high. Even in elderly patients, compared with conventional surgery, emergency LA may have a more prominent clinical advantage for CA.

\section{References}

1. Guller U, Hervey S, Purves H, Muhlbaier LH, Peterson ED, Eubanks S, et al. Laparoscopic versus open appendectomy: outcomes comparison based on a large administrative database. Ann Surg 2004; 239: 43-52.

2. Mohamed AA, Mahran KM. Laparoscopic appendectomy in complicated appendicitis: Is it safe? J Minim Access Surg 2013; 9: 55-58.

3. Lien SS, Kosik RO, Fan AP, Huang L, Zhao X, Chang X, et al. 10-year trends in the production and attrition of Chinese medical graduates: an analysis of nationwide data. Lancet 2016; 388: S11.
4. Rosin D. Value of laparoscopic appendectomy in the elderly. World J Surg 2009; 33: 923-924.

5. Gurleyik G, Gurleyik E. Age-related clinical features in older patients with acute appendicitis. Eur J Emerg Med 2003; 10 : 200-203.

6. Ward NT, Ramamoorthy SL, Chang DC, Parsons JK. Laparoscopic appendectomy is safer than open appendectomy in an elderly population. JSLS 2014; 18.

7. Horvath P, Lange J, Bachmann R, Struller F, Konigsrainer A, Zdichavsky M. Comparison of clinical outcome of laparoscopic versus open appendectomy for complicated appendicitis. Surg Endosc 2017; 31: 199-205.

8. Hanna MH, Hwang GS, Phelan MJ, Bui TL, Carmichael JC, Mills SD, et al. Laparoscopic right hemicolectomy: short- and long-term outcomes of intracorporeal versus extracorporeal anastomosis. Surg Endosc 2016; 30: 3933-3942.

9. Kirshtein B, Perry ZH, Mizrahi S, Lantsberg L. Value of laparoscopic appendectomy in the elderly patient. World J Surg 2009; 33: 918-922.

10. Taguchi Y, Komatsu S, Sakamoto E, Norimizu S, Shingu Y, Hasegawa H. Laparoscopic versus open surgery for complicated appendicitis in adults: a randomized controlled trial. Surg Endosc 2016; 30: 1705-1712.

11. Jeon BG, Kim HJ, Jung KH, Kim SW, Park JS, Kim KH, et al. Prolonged operative time in laparoscopic appendectomy: Predictive factors and outcomes. Int J Surg 2016; 36: 225-232.

12. Kotaluoto S, Ukkonen M, Pauniaho SL, Helminen M, Sand J, Rantanen T. Mortality related to appendectomy; a population based analysis over two decades in Finland. World J Surg 2017; 41: 64-69.

13. Svensson E, Horvath-Puho E, Stokholm MG, Sorensen HT, Henderson VW, Borghammer P. Appendectomy and risk of Parkinson's disease: A nationwide cohort study with more than 10 years of follow-up. Mov Disord 2016; 31: 1918-1922.

14. AzizO, Athanasiou T, Tekkis PP, Purkayastha S, Haddow J, Malinovski V, et al. Laparoscopic versus open appendectomy in children: a meta analysis. Ann Surg 2006; 243: 17-27.

15. Thomson JE, Kruger D, Jann-Kruger C, Kiss A, OmoshoroJones JA, Luvhengo T, et al. Laparoscopic versus open surgery for complicated appendicitis: a randomized controlled trial to prove safety. Surg Endosc 2015; 29: 2027-2032.

16. Jenkins PC, Oerline MK, Mullard AJ, Englesbe MJ, Campbell DJ, Hemmila MR. Hospital variation in outcomes following appendectomy in a regional quality improvement program. $\mathrm{Am}$ J Surg 2016; 212: 857-862.

17. Garcell HG, Arias AV, Sandoval CA, Garcia EG, Gamboa ME, Sado $A B$, et al. Incidence and etiology of surgical site infections in appendectomies: a 3-year prospective study. Oman Med J 2017; 32: 31-35.

18. Schlottmann F, Reino R, Sadava EE, Campos AA, Rotholtz NA. Could an abdominal drainage be avoided in complicated acute appendicitis? Lessons learned after 1300 laparoscopic appendectomies. Int J Surg 2016; 36: 40-43.

19. Schlottmann F, Sadava EE, Pena ME, Rotholtz NA. Laparoscopic Appendectomy: Risk Factors for Postoperative Intraabdominal Abscess. World J Surg 2017; 41: 1254-1258. 